\title{
Evaluasi Kinerja Perusahaan Berdasarkan Perspektif Organisasi, Proses, dan Staf Berbasis AHP dan OMAX
}

\author{
Ratih Ardia Sari*, Rahmi Yuniarti, Farida Risqi Nur Safitri \\ Jurusan Teknik Industri, Fakultas Teknik, Universitas Brawijaya \\ Jl. M.T. Haryono no 167 Malang \\ *Korespondensi penulis, surel: rath.ardia@ub.ac.id
}

\begin{abstract}
Performance measurement is done to measure the achievement of the company. Performance is made to know the company is reaching its target. In this research, the company's performance in the field of electrical contractor is measured. Key Performance Indicator (KPI) used from the perspective of the organization, process, and staff. Weighting KPI using Analytical Hierarchy Process. Objective Matrix and Traffic Light System are used for the scoring system. The results showed that from 23 KPI got 9 KPI is in the red zone, 10 in the yellow zone and the rest in the green zone. From these results then the company needs improvement to improve performance.
\end{abstract}

Keywords: Analytical Hierarchy Process (AHP), Quantum Performance Measurement Model (QPMM), Objective Matrix (OMAX), Performance measurement, Traffic Light System (TLS).

\begin{abstract}
Abstrak
Pengukuran kinerja dilakukan untuk mengukur pencapaian perusahaan. Kinerja dibuat untuk mengetahui perusahaan mencapai target yang dibuat. Pada penelitian ini dilakukan pengukuran kinerja pada perusahaan di bidang kontraktor listrik. Key Performance Indicator (KPI) yang digunakan dari perspektif organisasi, proses dan staff. Pembobotan KPI menggunakan Analytical Hierarchy Process. Objective Matrix dan Traffic Light System digunakan untuk scoring system. Hasil penelitian menunjukkan dari 23 KPI didapatkan 9 KPI berada pada zona merah, 10 pada zona kuning dan sisanya pada zona hijau. Dari hasil tersebut maka perusahaan memerlukan perbaikan untuk meningkatkan kinerja.
\end{abstract}

Kata kunci: Analytical Hierarchy Process (AHP), Quantum Performance Measurement Model (QPMM), Objective Matrix (OMAX), Pengukuran Kinerja, Traffic Light System (TLS).

\section{Pendahuluan}

Pengukuran kinerja merupakan proses mengukur dan mencatat hasil yang dicapai dari pelaksanaan kegiatan sesuai dengan misi berdasarkan hasil yang didapatkan [1]. Pengukuran kinerja dilakukan untuk melihat apakah perusahaan sudah memenuhi dan mencapai target yang dibuat. Selain itu, pengukuran kinerja dapat melihat apakah perusahaan sudah dapat memenuhi apa yang diinginkan oleh stakeholder perusahaan tersebut. Obyek amatan penelitian adalah perusahaan kontraktor listrik rekanan dari PT. PLN Persero (Area). Perusahaan ini bergerak dalam bidang jasa untuk bekerja sama dengan PLN dalam mengerjakan suatu proyek dalam bidang kelistrikan. Jumlah karyawan berjumlah 2 orang dan 12 pekerja sebagai pelaksana proyek. Perusahaan telah mengerjakan lebih dari puluhan proyek kelistrikan. Perusahaan ini dituntut untuk terus memberikan kepuasan kepada klien. Cara yang dilakukan adalah memberikan service yang bagus, material yang berkualitas, serta waktu pengerjaan proyek sesuai dengan kontrak. Pada saat ini, pengukuran kinerja perusahaan kontraktor listrik umumnya hanya mempertimbangkan aspek 
finansial dan waktu. Kinerja perusahaan dikatakan baik apabila biaya pemasukan lebih besar dari pengeluaran dan waktu penyelesaian proyek sesuai dengan kontrak yang telah disepakati. Apabila pengukuran kerja hanya ditinjau dari aspek finansial dan waktu saja, kepuasan stakeholders belum tentu dapat tercapai. Oleh karena itu dibutuhkan metode penilaian kinerja yang dapat mengukur kinerja perusahaan dengan mempertimbangkan aspek lain selain finansial dan waktu yang mudah dilakukan berbasis pada proses serta memberikan kepuasan kepada stakeholder.

Banyak metode pengukuran kinerja yang telah digunakan oleh perusahaan. Setiap organisasi menggunakan metode pengukuran kinerja berdasarkan kebutuhan organisasi tersebut. Penggunaan metode yang sesuai bertujuan terciptanya perusahaan yang efektif. Penelitian terdahulu yang berkaitan dengan pengukuran kinerja telah banyak dilakukan baik untuk organisasi yang bergerak di bidang manufaktur maupun jasa. Wibowo and Sholeh [2] melakukan analisis terhadap performansi supply chain pada proyek konstruksi dengan menggunakan metode SCOR. Penelitian yang dilakukan oleh Agitasari, et al. [3] melakukan identifikasi strategy objective dengan menggunakan SMART system, pembobotan dengan metode Analytical Hierarchy Process (AHP) dan perhitungan scoring dengan OMAX TLS di perusahaan yang bergerak di bidang penyamakan kulit. Selain itu penelitian Dewi et al [4] melakukan perancangan sistem pengukuran kinerja pada perusahaan eksplorasi dan eksploitasi minyak bumi dengan menggunakan Metode Balanced Scorecard dan AHP. Dari beberapa penelitian terdahulu ini, masing-masing organisasi dapat memilih metode pengukuran kinerjanya yang sesuai. SCOR menggunakan 5 perspektif dalam mengukur kinerja supply chain, BSC menggunakan 4 perspektif dan SMART menggunakan 3 perspektif [5]. Perspektif dari masing-masing metode disesuaikan dengan kondisi perusahan. Pada perusahaan yang bergerak di bidang jasa konstruksi listrik, umumnya menginginkan pengukuran kinerja yang mudah dilakukan dan mempertimbangkan perspektif organisasi, proses bisnis, dan staff yang dikombinasikan dengan kualitas, waktu dan biaya. Oleh karena itu, pada penelitian ini mencoba menggunakan pengukuran kinerja yang memiliki perspektif yang berbeda dengan metode pengukuran kinerja BSC, SMART dan SCOR dengan menggunakan perspektif organisasi, proses, dan staff yang dikombinasikan dengan kualitas, waktu dan biaya serta hubungan antara kualitas, waktu dan biaya berdasarkan yang dinamakan Quantum Performance Measurement Model (QPMM).

Penelitian terdahulu mengenai pengukuran kinerja dengan menggunakan metode QPMM masih relatif terbatas. Konsep pengukuran kinerja dalam QPMM memiliki tujuan untuk meningkatkan kemampuan perusahaan, di mana khususnya pada ukuran kualitas, waktu dan biaya [6]. Konsep organisasi dilakukan melalui tingkat organisasi, proses dan staff yang dikombinasikan dengan hubungan kualitas, waktu dan biaya. Metode ini lebih mudah dilakukan dan lebih sesuai dengan kondisi pada perusahaan konstruksi listrik. Selain itu, dengan metode ini, perspektif dalam menilai kinerja organisasi lebih mudah disesuaikan dari sistem pengukuran kinerja yang selama ini dilakukan. Penelitian ini berusaha melakukan pengukuran kinerja organisasi di bidang konstruksi listrik dengan menggunakan Key Performance Indicator (KPI) yang dihasilkan dari metode QPMM yang memiliki perspektif yang sesuai dengan obyek amatan.

Pengukuran kinerja berdasarkan QPMM merupakan sistem pengukuran kinerja yang diperkenalkan dengan strategi perusahaan dan mengendalikan tingkat pencapaian target. Pendekatan ini dikembangkan oleh Hronec [6]. Quantum kinerja didefinisikan sebagai sebuah tingkat pencapaian nilai dan layanan bagi seluruh stakeholder. Metode ini menyatakan bahwa kinerja yang unggul adalah hasil dari sistem perencanaan dan kontrol yang terintegrasi dari ketiga perspektif (organisasi, 
proses dan orang) yang dilihat dari sisi biaya, kualitas dan waktu [7]. Hubungan biaya dan kualitas menggambarkan hubungan nilai (pelanggan membutuhkan kualitas tinggi dengan biaya yang memadai), hubungan antara kualitas dan waktu merupakan hubungan layanan (kualitas pembelian dan waktu yang diperlukan untuk pembelian). Berdasarkan perihal ini, dimensi dan hubungan yang berbeda dari biaya, kualitas dan waktu harus dioptimalkan secara bersamaan. Tiap perspektif dikombinasikan dengan dimensi biaya, kualitas, dan waktu untuk membentuk Matrix Quantum pengukuran kinerja seperti pada Tabel 1 [8]. QPMM cocok ketika ingin diterapkan untuk pengukuran kinerja yang bergerak dibidang produk maupun jasa [6]. Pembobotan KPI dilakukan dengan menggunakan metode Analytical Hierarchy Process (AHP). Metode ini sering digunakan untuk pengambilan keputusan dalam menyelesaikan masalahmasalah dalam hal perencanaan, penentuan alternatif, penyusunan prioritas, pemilihan kebijakan, alokasi sumber daya, penentuan kebutuhan, peramalan hasil, perencanaan hasil, perencanaan sistem, pengukuran performansi, optimasi dan pemecahan konflik [9]. Selanjutnya penilaian kinerja dilakukan dengan menggunakan metode Objective Matrix (OMAX) Traffic Light System (TLS). Metode penilaian kinerja OMAX TLS digunakan karena lebih mudah dipahami, terlihat dengan sangat jelas mana target yang belum tercapai dan butuh perbaikan dengan segera, mana yang sudah tercapai.

Tabel 1 Matriks Quantum Performance Measurement Model

\begin{tabular}{|c|c|c|c|}
\hline & \multicolumn{3}{|c|}{ Quantum Performance } \\
\hline & \multicolumn{2}{|c|}{ Value } & \multirow{2}{*}{$\begin{array}{l}\text { Service } \\
\text { Time }\end{array}$} \\
\hline & Cost & Quality & \\
\hline Organization & $\begin{array}{l}\text { Financial } \\
\text { Operational } \\
\text { Strategic }\end{array}$ & $\begin{array}{l}\text { Empathy } \\
\text { Productivity } \\
\text { Reliability } \\
\text { Credibility } \\
\text { Competence }\end{array}$ & $\begin{array}{l}\text { Speed } \\
\text { Flexibility } \\
\text { Reactivity } \\
\text { Movability }\end{array}$ \\
\hline Process & $\begin{array}{l}\text { Input } \\
\text { Activities }\end{array}$ & $\begin{array}{l}\text { Consistency } \\
\text { Productivity }\end{array}$ & $\begin{array}{l}\text { Speed } \\
\text { Flexibility }\end{array}$ \\
\hline People & $\begin{array}{l}\text { Reimbursement } \\
\text { Development } \\
\text { Motivation }\end{array}$ & $\begin{array}{l}\text { Reliability } \\
\text { Credibility } \\
\text { Competence }\end{array}$ & $\begin{array}{l}\text { Reactivity } \\
\text { Movability }\end{array}$ \\
\hline
\end{tabular}

Pada penelitian-penelitian sebelumnya umumnya penilaian kinerja berdasarkan aspek finansial dan waktu. Namun, belum mengevaluasi penilaian kinerja berdasarkan perspektif organisasi, proses dan staf yang dikombinasikan dengan kualitas, waktu, dan biaya. Selain itu hubungan antara kualitas, waktu dan biaya dapat diketahui dengan jelas pada masing-masing perspektif. Penelitian ini menggunakan perspektif yang berbeda dengan metode yang digunakan pada metode pengukuran kinerja yang umum digunakan seperti BSC, PRISM atau SMART. Selain itu dalam QPMM memiliki kerangka matriks yang bisa dilihat dengan jelas dibandingkan dengan metode pengukuran kinerja yang lain, sehingga ketika ingin membandingkan antara satu perspektif dengan perspektif yang lain lebih mudah. Dari hasil penelitian ini diharapkan dapat memperkaya keilmuan dalam bidang pengukuran kinerja serta menjadi bahan pertimbangan dan sebagai masukan untuk perusahaan agar bisa mengetahui target mana saja yang belum dicapai perusahaan dan yang sudah dicapai, setelah mengetahui hal tersebut perusahaan juga bisa meningkatkan atau memperbaiki hal-hal yang belum tercapai. 


\section{Metode Penelitian}

Jenis penelitian yang digunakan adalah penelitian deskriptif yang bertujuan untuk memberikan gambaran atau deskripsi tentang suatu keadaan secara objektif. Penelitian diawali dengan melakukan studi lapangan dan literature yang berkaitan dengan metode QPMM, melakukan identifikasi masalah, rumusan masalah dan penentuan tujuan. Selanjutnya dilakukan pengumpulan data baik primer melalui wawancara ataupun pengisian kuesioner maupun data sekunder yang berupa penelitian terdahulu, profil perusahaan, budaya perusahaan, struktur organisasi, tujuan perusahaan, dan data-data internal perusahaan (sertifikat, daftar proyek, daftar alat dan biaya operasional).

Pengumpulan data KPI didasarkan pada tujuan perusahaan yang dilihat dari sisi perspektif dari metode QPMM serta dibuat strategy objective-nya serta di validasi oleh pihak perusahaan (direktur utama). Validasi dilakukan dengan cara pengisian kuesioner tertutup.

Pengolahan data dilakukan dengan melakukan pembobotan dari masing-masing perspektif, strategy objective dan KPI dengan menggunakan AHP. Nilai dari bobot ditentukan dari kuesioner perbandingan berpasangan. Dari pembobotan dilakukan scoring system dengan menggunakan metode OMAX dan rekomendasi perbaikan dilakukan sesuai indikator warna yang terdapat pada hasil TLS. Dari hasil pengolahan maka dilakukan pembahasan serta penarikan kesimpulan.

\section{Hasil dan Pembahasan}

Penilaian kinerja pada perusahaan kontraktor listrik ini dilakukan dengan identifikasi KPI dari perspektif QPMM. Penelitian ini menggunakan KPI yang telah diidentifikasi dan di validasi oleh Safitri, et al. [10] pada perusahaan yang sama. Berdasarkan hasil validasi secara keseluruhan didapatkan 23 KPI yang digunakan untuk mengukur kinerja pada perusahaan ini yang dapat dilihat pada Tabel 2 [10].

Pembobotan dilakukan dengan tujuan untuk menentukan tingkat kepentingan dan untuk mengekspresikan seberapa besar pengaruh suatu parameter terhadap parameter lainnya yang ada pada perspektif QPMM, strategy objective dan (jumlah KPI) KPI yang telah tervalidasi, dengan nilai rasio inkonsisten (CR) yaitu $\leq 0,1$ dikatakan konsisten atau bobot dapat diterima. Hasil dari pembobotan dapat dilihat pada Tabel 3. Dari Tabel 3 dapat dilihat bahwa bobot dari perspektif kualitas-proses memiliki bobot terbesar yaitu sebesar 0,195 dan bobot terkecil ada pada perspektif waktu-staf yaitu sebesar 0,059 .

Metode yang digunakan untuk scoring system adalah Objective Matrix (OMAX) dan Traffic Light System (TLS). Objective Matrix merupakan suatu metode untuk mengukur kinerja yang mengevaluasi beberapa kriteria produktivitas dari bobot untuk memperoleh sebuah indeks dari keseluruhan produktivitas dari perusahaan [11]. Apabila tingkat pencapaian indikator kinerja sudah tidak dapat melebihi dari target yang ditentukan atau dengan kata lain sudah maksimum, maka diisikan pada level 10, tetapi apabila hasil pencapaian indikator kinerja dapat melebihi target yang ditentukan maka dapat diisikan pada level 8 [12]. Tingkat pencapaian semula yaitu tingkat pencapaian yang diperoleh ketika matriks mulai dioperasikan atau pencapaian kinerja pada tahun sebelumnya, ditempatkan pada level 3. Untuk level 0 diisi dengan nilai terendah yang mungkin dicapai oleh perusahaan pada kondisi paling buruk. 
Tabel 2 Daftar KPI Tervalidasi

\begin{tabular}{|c|c|c|}
\hline $\begin{array}{l}\text { Perspektif } \\
\text { QPMM }\end{array}$ & Kode & KPI \\
\hline $\begin{array}{l}\text { Kualitas- } \\
\text { Organisasi } \\
\text { (K-O) }\end{array}$ & $\begin{array}{l}\mathrm{K}-\mathrm{O}_{1} \mathrm{a} \\
\mathrm{K}-\mathrm{O}_{1} \mathrm{~b} \\
\mathrm{~K}-\mathrm{O}_{1} \mathrm{c} \\
\mathrm{K}-\mathrm{O}_{2} \mathrm{a} \\
\mathrm{K}-\mathrm{O}_{3} \mathrm{a}\end{array}$ & $\begin{array}{l}\text { Jumlah pelatihan yang diikuti oleh karyawan perusahaan } \\
\text { Jumlah seminar yang diikuti oleh perusahaan } \\
\text { Jumlah sertifikat penghargaan yang dimiliki oleh perusahaan } \\
\text { Jumlah proyek yang dikerjakan oleh perusahaan } \\
\text { Jumlah fasilitas yang disediakan perusahaan untuk memudahkan } \\
\text { pihak eksternal dalam mengakses informasi perusahaan }\end{array}$ \\
\hline $\begin{array}{l}\text { Kualitas- } \\
\text { Proses (K-P) }\end{array}$ & $\begin{array}{l}\mathrm{K}-\mathrm{P}_{1} \mathrm{a} \\
\mathrm{K}-\mathrm{P}_{1} \mathrm{~b} \\
\mathrm{~K}-\mathrm{P}_{2} \mathrm{a} \\
\mathrm{K}-\mathrm{P}_{3} \mathrm{a}\end{array}$ & $\begin{array}{l}\text { Persentase jumlah pengerjaan proyek yang tepat waktu } \\
\text { Persentase jumlah pengerjaan proyek yang sesuai dengan SPK } \\
\text { Jumlah kecelakaan kerja ketika pengerjaan proyek } \\
\text { Persentase jumlah alat yang sesuai standar }\end{array}$ \\
\hline $\begin{array}{l}\text { Kualitas- } \\
\text { Orang }(\mathrm{K}-\mathrm{H})\end{array}$ & $\begin{array}{l}\mathrm{K}-\mathrm{H}_{1} \mathrm{a} \\
\mathrm{K}-\mathrm{H}_{2} \mathrm{a} \\
\mathrm{K}-\mathrm{H}_{3} \mathrm{a} \\
\mathrm{K}-\mathrm{H}_{4} \mathrm{a} \\
\end{array}$ & $\begin{array}{l}\text { Persentase jumlah karyawan yang memiliki sertifikat dalam bidang } \\
\text { keahlian listrik dan K3 } \\
\text { Persentase jumlah karyawan yang memiliki sertifikat kompetensi } \\
\text { Jumlah evaluasi kerja yang diadakan oleh perusahaan tiap } \\
\text { tahunnya } \\
\text { Persentase jumlah karyawan yang absen kerja }\end{array}$ \\
\hline $\begin{array}{l}\text { Waktu- } \\
\text { Organisasi } \\
(\mathrm{W}-\mathrm{O})\end{array}$ & $\begin{array}{l}\mathrm{W}-\mathrm{O}_{1} \mathrm{a} \\
\mathrm{W}-\mathrm{O}_{2} \mathrm{a}\end{array}$ & $\begin{array}{l}\text { Rata-rata waktu yang digunakan untuk merespons keluhan dari } \\
\text { klien } \\
\text { Jumlah inovasi yang dilakukan oleh perusahaan tiap tahun }\end{array}$ \\
\hline $\begin{array}{l}\text { Waktu- } \\
\text { Proses } \\
\text { (W-P) }\end{array}$ & $\begin{array}{l}\mathrm{W}-\mathrm{P}_{1} \mathrm{a} \\
\mathrm{W}-\mathrm{P}_{2 \mathrm{a}}\end{array}$ & $\begin{array}{l}\text { Rata-rata waktu yang digunakan untuk menyelesaikan proyek } \\
\text { Jumlah proyek yang diselesaikan lebih awal sesuai keinginan klien }\end{array}$ \\
\hline $\begin{array}{l}\text { Waktu-Orang } \\
\text { (W-H) }\end{array}$ & $\mathrm{W}-\mathrm{H}_{1} \mathrm{a}$ & Persentase jumlah karyawan yang datang tepat waktu \\
\hline $\begin{array}{l}\text { Biaya- } \\
\text { Organisasi } \\
(\text { B-O) }\end{array}$ & $\mathrm{B}-\mathrm{O}_{1} \mathrm{a}$ & $\begin{array}{l}\text { Persentase biaya yang digunakan untuk pengembangan } \\
\text { perusahaan }\end{array}$ \\
\hline $\begin{array}{l}\text { Biaya-Proses } \\
\text { (B-P) }\end{array}$ & $\begin{array}{l}\mathrm{B}-\mathrm{P}_{1} \mathrm{a} \\
\mathrm{B}-\mathrm{P}_{1} \mathrm{~b}\end{array}$ & $\begin{array}{l}\text { Persentase biaya yang dikeluarkan untuk pembelian alat yang } \\
\text { digunakan selama proyek } \\
\text { Persentase biaya denda yang ditanggung karena keterlambatan }\end{array}$ \\
\hline $\begin{array}{l}\text { Biaya-Orang } \\
(\mathrm{B}-\mathrm{H})\end{array}$ & $\begin{array}{l}\mathrm{B}-\mathrm{H}_{1 \mathrm{a}} \\
\mathrm{B}-\mathrm{H}_{2} \mathrm{a}\end{array}$ & $\begin{array}{l}\text { Persentase biaya pengobatan untuk kecelakaan kerja } \\
\text { Persentase tenaga kerja yang menerima upah sesuai dengan } \\
\text { standar dari PLN }\end{array}$ \\
\hline
\end{tabular}

Metode yang digunakan untuk scoring system adalah Objective Matrix (OMAX) dan Traffic Light System (TLS). Objective Matrix merupakan suatu metode untuk mengukur kinerja yang mengevaluasi beberapa kriteria produktivitas dari bobot untuk memperoleh sebuah indeks dari keseluruhan produktivitas dari perusahaan [11]. Apabila tingkat pencapaian indikator kinerja sudah tidak dapat melebihi dari target yang ditentukan atau dengan kata lain sudah maksimum, maka diisikan pada level 10, tetapi apabila hasil pencapaian indikator kinerja dapat melebihi target yang ditentukan maka dapat diisikan pada level 8 [12]. Tingkat pencapaian semula yaitu tingkat pencapaian yang diperoleh ketika matriks mulai dioperasikan atau pencapaian kinerja pada tahun sebelumnya, ditempatkan pada level 3. Untuk level 0 diisi dengan nilai terendah yang mungkin dicapai oleh perusahaan pada kondisi paling buruk. 
Tabel 3 Hasil Pembobotan Keseluruhan

\begin{tabular}{|c|c|c|c|c|c|}
\hline Pers. & $\begin{array}{l}\text { Strategic } \\
\text { Objective }\end{array}$ & KPI & Bobot Pers. & Bobot SO & Bobot KPI \\
\hline \multirow{5}{*}{$\mathrm{K}-\mathrm{O}$} & \multirow{3}{*}{$\mathrm{K}-\mathrm{O}_{1}$} & $\mathrm{~K}-\mathrm{O}_{1} \mathrm{a}$ & \multirow{5}{*}{0,140} & \multirow{3}{*}{0,352} & 0,260 \\
\hline & & $\mathrm{K}-\mathrm{O}_{1} \mathrm{~b}$ & & & 0,327 \\
\hline & & $\mathrm{K}-\mathrm{O}_{1} \mathrm{c}$ & & & 0,413 \\
\hline & $\mathrm{K}-\mathrm{O}_{2}$ & $\mathrm{~K}-\mathrm{O}_{2} \mathrm{a}$ & & 0,559 & 1 \\
\hline & $\mathrm{K}-\mathrm{O}_{3}$ & $\mathrm{~K}-\mathrm{O}_{3} \mathrm{a}$ & & 0,089 & 1 \\
\hline \multirow{4}{*}{$\mathrm{K}-\mathrm{P}$} & & $\mathrm{K}-\mathrm{P}_{1} \mathrm{a}$ & \multirow{4}{*}{0,195} & \multirow{2}{*}{0,387} & 0,5 \\
\hline & $\mathrm{K}-\mathrm{P}_{1}$ & $\mathrm{~K}-\mathrm{P}_{1} \mathrm{~b}$ & & & 0,5 \\
\hline & $\mathrm{K}-\mathrm{P}_{2}$ & $\mathrm{~K}-\mathrm{P}_{2 \mathrm{a}}$ & & 0,443 & 1 \\
\hline & K-P $P_{3}$ & K-P & & 0,169 & 1 \\
\hline \multirow{4}{*}{$\mathrm{K}-\mathrm{H}$} & $\mathrm{K}-\mathrm{H}_{1}$ & $\mathrm{~K}-\mathrm{H}_{1} \mathrm{a}$ & \multirow{4}{*}{0,092} & 0,389 & 1 \\
\hline & $\mathrm{K}-\mathrm{H}_{2}$ & $\mathrm{~K}-\mathrm{H}_{2} \mathrm{a}$ & & 0,303 & 1 \\
\hline & $\mathrm{K}-\mathrm{H}_{3}$ & $\mathrm{~K}-\mathrm{H}_{3} \mathrm{a}$ & & 0,178 & 1 \\
\hline & $\mathrm{K}-\mathrm{H}_{4}$ & $\mathrm{~K}-\mathrm{H}_{4} \mathrm{a}$ & & 0,130 & 1 \\
\hline \multirow[b]{2}{*}{ W-O } & $\mathrm{W}-\mathrm{O}_{1}$ & $\mathrm{~W}-\mathrm{O}_{1} \mathrm{a}$ & \multirow[b]{2}{*}{0,064} & 0,75 & 1 \\
\hline & $\mathrm{W}-\mathrm{O}_{2}$ & $\mathrm{~W}-\mathrm{O}_{2} \mathrm{a}$ & & 0,25 & 1 \\
\hline \multirow{2}{*}{ W-P } & W-P 1 & $\mathrm{~W}-\mathrm{P}_{1} \mathrm{a}$ & \multirow{2}{*}{0,095} & 0,8 & 1 \\
\hline & W-P $\mathrm{P}_{2}$ & W-P $\mathrm{P}_{2 \mathrm{a}}$ & & 0,2 & 1 \\
\hline W-H & $\mathrm{W}-\mathrm{H}_{1}$ & $\mathrm{~W}-\mathrm{H}_{1} \mathrm{a}$ & 0,059 & 1 & 1 \\
\hline B-O & $\mathrm{B}-\mathrm{O}_{1}$ & $\mathrm{~B}-\mathrm{O}_{1} \mathrm{a}$ & 0,126 & 1 & 1 \\
\hline \multirow{2}{*}{ B-P } & \multirow{2}{*}{$\mathrm{B}-\mathrm{P}_{1}$} & $\mathrm{~B}-\mathrm{P}_{1} \mathrm{a}$ & \multirow{2}{*}{0,150} & 1 & 0,75 \\
\hline & & $\mathrm{B}-\mathrm{P}_{1} \mathrm{~b}$ & & & 0,25 \\
\hline \multirow{2}{*}{ B-H } & B-H $H_{1}$ & B-H $\mathrm{H}_{1 \mathrm{a}}$ & \multirow{2}{*}{0,078} & 0,2 & 1 \\
\hline & B-H ${ }_{2}$ & B-H ${ }_{2} \mathrm{a}$ & & 0,8 & 1 \\
\hline
\end{tabular}

TLS termasuk dalam penilaian OMAX, yang berhubungan dengan scoring system yang digunakan sebagai tanda score yang diperoleh dari suatu indikator kinerja apakah memerlukan perbaikan atau tidak. Indikator yang ada pada TLS direpresentasikan dalam tiga warna yaitu merah, kuning dan hijau. Warna merah menandakan bahwa suatu indikator kinerja masih berada di bawah target yang telah ditentukan dan berada pada ambang batas 0 sampai 3. Warna kuning, menandakan belum tercapai target meskipun nilai yang didapat sudah mendekati target yang ditentukan, berada pada ambang batas 4 sampai dengan 7 . Warna hijau, dengan ambang batas 8 sampai dengan 10 yang menandakan telah mencapai, tepat pada target atau bahkan melampaui target yang ditetapkan. Dari hasil perhitungan OMAX TLS untuk masing-masing perspektif kemudian dilakukan pengukuran kinerja keseluruhan dari perusahaan sehingga didapatkan nilai indeks total kinerja perusahaan yang dapat dilihat pada Tabel 4.

Dari hasil Tabel 4 didapatkan hasil total indeks kinerja perusahaan kontraktor listrik sebesar 4,27 nilai tersebut berada pada zona kuning yang berarti bahwa secara keseluruhan kinerja perusahaan masih belum mencapai target yang ingin dicapai meskipun nilainya sudah mendekati target. Dilihat dari hasil tersebut, maka perusahaan memerlukan perbaikan untuk meningkatkan kinerja, serta harus berhatihati dengan adanya berbagai kemungkinan yang akan muncul, yang nantinya dapat menurunkan kinerja perusahaan, terutama dalam hal ini dilihat dari perspektif yang ada pada QPMM. Hasil penentuan menggunakan TLS dapat dilihat pada Tabel 5. Dilihat dari KPI yang sudah dihitung menggunakan metode OMAX TLS, didapatkan hasil bahwa setiap KPI berada pada zona-zona tertentu yaitu zona merah, kuning dan hijau. Dari 23 KPI tersebut didapatkan hasil 9 KPI berada pada zona merah, 10 pada zona kuning dan 4 pada zona hijau 
Tabel 4 Skema Pengukuran Kinerja Perusahaan Kontraktor Listrik (Perspektif)

\begin{tabular}{lccc}
\hline & \multicolumn{3}{c}{ Quantum Performance } \\
\cline { 2 - 4 } & Cost & Quality & Service \\
\cline { 2 - 4 } Organization & 1,52 & 4,63 & Time \\
\hline Process & 1,46 & 7,87 & 3,01 \\
\hline People & 5,3 & 4,71 & 1,40 \\
\hline \multicolumn{3}{c}{ Total Indeks Kinerja Perusahaan Kontraktor Listrik } \\
\hline \multicolumn{4}{c}{$\mathbf{4 , 2 7}$} \\
\hline
\end{tabular}

Tabel 5 Daftar KPI pada Zona Hijau, Kuning, Merah

\begin{tabular}{|c|c|c|c|c|c|}
\hline $\begin{array}{c}\text { Kategori } \\
\text { TLS }\end{array}$ & Kode KPI & $\begin{array}{c}\text { Kategori } \\
\text { TLS }\end{array}$ & Kode KPI & $\begin{array}{l}\text { Kategori } \\
\text { TLS }\end{array}$ & Kode KPI \\
\hline \multirow{10}{*}{ Hijau } & $\mathrm{K}-\mathrm{P}_{2} \mathrm{a}$ & \multirow{10}{*}{ Kuning } & $\mathrm{K}-\mathrm{O}_{1} \mathrm{a}$ & \multirow{10}{*}{ Merah } & $\mathrm{K}-\mathrm{H}_{1} \mathrm{a}$ \\
\hline & $\mathrm{K}-\mathrm{P}_{3} \mathrm{a}$ & & $\mathrm{K}-\mathrm{O}_{1} \mathrm{~b}$ & & $\mathrm{~K}-\mathrm{H}_{4} \mathrm{a}$ \\
\hline & $\mathrm{K}-\mathrm{H}_{3} \mathrm{a}$ & & $\mathrm{K}-\mathrm{O}_{1} \mathrm{c}$ & & $\mathrm{W}-\mathrm{O}_{2} \mathrm{a}$ \\
\hline & \multirow[t]{7}{*}{$\mathrm{W}-\mathrm{H}_{1} \mathrm{a}$} & & $\mathrm{K}-\mathrm{O}_{2} \mathrm{a}$ & & $\mathrm{W}-\mathrm{P}_{1} \mathrm{a}$ \\
\hline & & & $\mathrm{K}-\mathrm{O}_{3} \mathrm{a}$ & & $\mathrm{W}-\mathrm{P}_{2} \mathrm{a}$ \\
\hline & & & $\mathrm{K}-\mathrm{P}_{1} \mathrm{a}$ & & $\mathrm{B}-\mathrm{O}_{1} \mathrm{a}$ \\
\hline & & & $\mathrm{K}-\mathrm{P}_{1} \mathrm{~b}$ & & B-P1a \\
\hline & & & $\mathrm{K}-\mathrm{H}_{2} \mathrm{a}$ & & B-P1b \\
\hline & & & W-O1a & & B-H1a \\
\hline & & & B-H2a & & \\
\hline
\end{tabular}

KPI yang berada pada zona merah mendapatkan prioritas utama atau terlebih dahulu mendapatkan tindakan perbaikan, dengan harapan rekomendasi perbaikan tersebut dapat dijadikan pertimbangan agar kinerja dapat meningkat [13], serta kriteria yang paling dominan mendapatkan skor dibawah 2 pada metode TLS maka akan dilakukan perbaikan menggunakan salah satu metode quality tools [14].

Rekomendasi yang dapat diberikan untuk permasalahan pada zona merah salah satunya yaitu membentuk divisi Human Resource and Development (HRD). Setelah divisi HRD terbentuk, divisi tersebut bertugas membuat perencanaan yang tersusun dengan baik tentang pelatihan yang akan diikuti oleh karyawan, menentukan kapan pelatihan yang akan diikuti oleh karyawan perusahaan, menentukan jadwal yang sesuai dengan waktu luang karyawan, menentukan dalam satu kali pelatihan diikuti oleh berapa karyawan dan siapa saja karyawan yang ditunjuk perusahaan, pengalokasian biaya untuk pelatihan sehingga karyawan tidak perlu mengeluarkan uang untuk mengikuti pelatihan. Untuk menghindari karyawan yang resign setelah mengikuti pelatihan, maka perusahaan perlu membuat kontrak tertulis dengan karyawan, bahwa sertifikat yang telah didapatkan akan digunakan semaksimal mungkin sebagai pengembangan diri karyawan tersebut di dalam maupun di luar perusahaan kontraktor listrik. Perusahaan bisa menegakkan peraturan perusahaan secara konsisten dan penuh ketegasan, peraturan berisi tentang berbagai kebijakan dan peraturan perusahaan yang harus dipatuhi oleh seluruh karyawan tanpa terkecuali.

Rekomendasi yang lain yang dapat dilakukan perusahaan yaitu melakukan pengaturan shift kerja pada 12 man power yang dimiliki agar tidak terjadi overload kerja pada beberapa man power, menyeimbangkan lama kerja dalam satu minggu setiap man power agar tidak terjadi penumpukan kerja pada beberapa man power. Perusahaan 
bisa membuat perencanaan shift jaga proyek ketika proyek sedang dilakukan. Pengawasan terdiri dari dua aktivitas yaitu pengawasan secara keseluruhan dan pengecekan pengerjaan.

Untuk inovasi produk, rekomendasi yang dapat dilakukan perusahaan ialah mengadakan pertemuan atau meeting setiap satu kali dalam tiga bulan yang membahas mengenai inovasi-inovasi untuk pengembangan usaha baru yang dapat dikembangkan oleh perusahaan serta perusahaan melakukan benchmarking ke perusahaan yang sejenis dengan cara perusahaan kontraktor listrik membentuk sebuah tim marketing yang bertugas mencari tahu mengenai informasi perusahaan-perusahaan sejenis, serta memilah-milah keunggulan mana yang bisa diadopsi oleh perusahaan. Benchmarking dilakukan dengan tanpa meninggalkan ciri khas atau core bisnis dari perusahaan kontraktor listrik, serta dapat memenuhi target sesuai dengan tujuan perusahaan.

Selain itu, perusahaan bisa merencanakan pembelian alat sebelum proyek dilakukan, perencanaan pembelian alat tidak hanya dilakukan oleh satu orang saja sehingga bisa lebih cepat dan saling mengingatkan ketika ada yang alat yang kurang. Permintaan yang mendadak dari pihak klien tentu dapat diatasi dengan cara menambahkan poin pada kesepakatan awal bahwa ketika klien menginginkan percepatan penyelesaian proyek, maka harus memberitahukan kepada pihak perusahaan kontraktor listrik H-30 hari dari batas penyelesaian proyek. Pengambilan keputusan oleh pihak perusahaan kontraktor listrik mana sajakah supplier yang bisa diajak bekerja sama, survey pasar bisa diagendakan satu kali dalam sebulan. Semakin banyak supplier yang diajak bekerja sama, maka jadi lebih banyak memiliki variasi supplier.

Di samping itu perusahaan dapat membuat perencanaan dalam satu periode dengan melihat dan mengevaluasi dari periode sebelumnya. Sosialisasi target perlu diketahui untuk memicu sumber daya manusia dalam perusahaan agar berusaha untuk mencapai target tersebut. Perusahaan bisa melakukan rapat koordinasi di setiap awal periode yang dihadiri oleh seluruh elemen perusahaan. Perusahaan juga disarankan untuk membuat SOP mengenai penggunaan APD yang benar, pembuatan SOP bisa dilakukan oleh karyawan dalam perusahaan yang sudah memiliki sertifikat K3 serta membuat sebuah program untuk mengurangi kelelahan kerja, dan memastikan bahwa lama bekerja dan lama istirahat seimbang.

\section{Simpulan}

Kesimpulan dari penelitian mengenai pengukuran kinerja perusahaan kontraktor listrik menggunakan perspektif QPMM serta scoring system menggunakan metode OMAX TLS adalah total indeks kinerja perusahaan sebesar 4,27 nilai tersebut berada pada zona kuning yang berarti bahwa secara keseluruhan kinerja perusahaan masih belum mencapai target yang telah ditentukan meskipun nilainya mendekati. Dari keseluruhan indikator kinerja yang berada pada zona merah, dapat ditarik kesimpulan bahwa, semua indikator kinerja yang berada pada zona merah tersebut disebabkan karena kurangnya perencanaan SDM dengan rekomendasi pembentukan divisi HRD, penjadwalan pelatihan yang baik, serta pemberian reward berupa insentif kepada pekerja yang tidak melakukan absen kerja selama satu periode masa kerjanya. Perencanaan proyek dengan rekomendasi rencana pengerjaan dari setiap proyek, kendala yang mungkin muncul dari setiap pengerjaan proyek, biaya yang dikeluarkan, alokasi pekerja dalam pengerjaan proyek, perencanaan pembelian alat, pembuatan SOP untuk APD yang digunakan selama pengerjaan proyek, penjadwalan monitoring proyek, serta pembuatan sekaligus penyampaian target penyelesaian setiap proyek kepada 
seluruh karyawan perusahaan. Perencanaan biaya dengan rekomendasi pembentukan divisi finansial yang khusus bertanggung jawab dalam keuangan perusahaan. Saran untuk penelitian selanjutnya adalah menambahkan perspektif baru dalam model QPMM.

\section{Referensi}

[1] moeheriono, pengukuran kinerja berbasis kinerja, edisi revisi. Jakarta: pt. Raja grafindo persada, 2012.

[2] m. A. Wibowo and m. N. Sholeh, "the analysis of supply chain performance measurement at construction project," procedia engineering, vol. 125, pp. 25-31, 2015.

[3] r. A. Agitasari, r. Y. Efranto, and d. Hardiningtyas, "analisis pengukuran kinerja operasional perusahaan kulit dengan strategic measurement analysis and reporting technique (smart) system," jurnal rekayasa dan manajemen sistem industri, vol. 4, 2016.

[4] a. C. Dewi, alina, a. N. Zaman, m. As'adi, "perancangan sistem pengukuran kinerja menggunakan metode balanced scorecard dan analytical hierarchy process," presented at the prosiding snti dan satelit 2017, malang, 2017.

[5] d. Wibisono, "a framework of performance measurement system for manufacturing company," the south east asian journal of management, 2012.

[6] s. M. Hronec, vital signs-using quality, time, and cost performance measurements to chart your company's future, 1993.

[7] j. Tidd, from knowledge management to strategic competence: measuring technological, market and organizational innovation: world scientific publishing co. Pte. Ltd., 2000.

[8] t. Limberg, examining innovation management from a fair process perspective: springer, 2008.

[9] t. L. Saaty, "pengambilan keputusan bagi para pemimpin, proses hirarki analitik untuk pengambilan keputusan dalam situasi yang kompleks," pustaka binama pressindo, vol. 100, 1993.

[10] f. R. N. Safitri, r. Yuniarti, and r. A. Sari, "penentuan key performance indicator menggunakan metode quantum performance measurement model," jurnal rekayasa dan manajemen sistem industri, vol. 5, pp. P1020-1024, 2017.

[11] j. L. Riggs, production systems: planning, analysis, and control: new york: john willey and sons, 1986.

[12] c. G. T. W. F. Christopher, "measurement and improvement," in handbook for productivity, ed: portland: productivity press, 2003.

[13] f. S. Handika, n. W. Setyanto, and r. Y. Efranto, "penggunaan metode balanced scorecard sebagai upaya meningkatkan kinerja perusahaan berbasis analytical hierarchy process dan objectives matrix (studi kasus: pt. Bank x (persero) tbk. Malang)," jurnal rekayasa dan manajemen sistem industri, vol. 1, pp. P144-151, 2013.

[14] p. B. K. Sirajuddin and k. C. Jaya, "Pengukuran Kinerja Produktivitas Perusahaan Dengan Metode Objective Matrix (OMAX)," Paper IENACO, 2013. 